\title{
Simultaneous hepatic iron and fat quantification with dual-energy CT in a rabbit model of coexisting iron and fat
}

\author{
Yun Peng ${ }^{1 \#}$, Jing Ye ${ }^{1 \#}$, Chang Liu ${ }^{1}$, Hongru Jia ${ }^{1}$, Jun Sun ${ }^{1}$, Jun Ling ${ }^{1}$, Martin Prince ${ }^{2}$, Chang Li ${ }^{3}$, \\ Xianfu Luo ${ }^{1 \wedge}$ \\ ${ }^{1}$ Department of Radiology, Northern Jiangsu People's Hospital, Clinical Medical College, Yangzhou University, Yangzhou, China; ${ }^{2}$ Department \\ of Radiology, Weill Medical College of Cornell University, New York, NY, USA; ${ }^{3}$ Department of Radiology, Sun Yat-sen Memorial Hospital, \\ Sun Yat-sen University, Guangzhou, China \\ "These authors contributed equally to this work.
}

Correspondence to: Xianfu Luo. Department of Radiology, Northern Jiangsu People’s Hospital, Clinical Medical College, Yangzhou University, No. 98 Nantong West Road, Yangzhou 225001, China. Email: xianfu-luo@hotmail.com.

Background: Liver iron and fat are often co-deposited, synergistically aggravating the progression of chronic liver disease. Accurate determination of liver iron and fat content is helpful for patient management. To assess the accuracy of hepatic iron/fat decomposition using dual-energy computed tomography (DECT) for simultaneously quantifying hepatic iron and fat when both are present.

Methods: Sixty-eight New Zealand rabbits on a high-fat/cholesterol diet plus iron injections were used to establish a model of coexisting hepatic iron/fat. Abdominal imaging was performed using dual-source DECT. The iron and fat fractions (Iron- ${ }_{\mathrm{CT}}$ and Fat $^{-}{ }_{\mathrm{CT}}$, respectively) were calculated using a 3-material decomposition algorithm. The spectroscopic liver iron concentration (LIC) grading (normal, mild, moderate, severe, and massive iron overload) and the histopathological fat fraction (Fat-ref) grading (normal, mild, moderate, severe steatosis) were used as references. Correlations between the DECT parameters and the references were analyzed. Hepatic iron/fat quantification equations were established and validated. Analysis of covariance was used to assess the influence of fat on iron measurements and vice versa.

Results: Iron- ${ }_{\mathrm{CT}}$ highly correlated with $\mathrm{LIC}(\mathrm{r}=0.94, \mathrm{P}<0.001)$, and Fat- ${ }_{\mathrm{CT}}$ highly correlated with Fat- ${ }_{\text {ref }}$ $(\mathrm{r}=0.88, \mathrm{P}<0.001)$. Both the Iron- ${ }_{\mathrm{CT}^{-}}$and $\mathrm{Fat}^{-}{ }_{\mathrm{CT}}$-derived LIC and fat fraction showed good agreement with spectroscopy/histology. The linear relationship between Iron- ${ }_{\mathrm{CT}}$ and spectroscopic LIC was not affected by the grade of hepatic fat $(\mathrm{F}=1.93, \mathrm{P}=0.16)$. The linear relationship between Fat ${ }_{\mathrm{C}}{ }_{\text {and }} \mathrm{Fat}{ }^{-}$ref was unaffected by hepatic iron grades from normal to severe $(\mathrm{F}=0.18, \mathrm{P}=0.91)$. However, with massive iron overload $[>15.0 \mathrm{mg} \mathrm{Fe} / \mathrm{g}(270 \mu \mathrm{mol} / \mathrm{g})]$ the regression began to deviate, causing fat underestimation $(\mathrm{F}=5.50, \mathrm{P}=0.04)$.

Conclusions: Our DECT-based iron/fat decomposition algorithm accurately measured hepatic iron and fat when both were present in a rabbit model. Hepatic fat may be underestimated when there is massive iron overload.

Keywords: Dual-energy scanned projection radiography; fatty liver; iron overload; X-ray computed tomography

Submitted Jul 23, 2020. Accepted for publication Nov 23, 2020.

doi: 10.21037/qims-20-902

View this article at: http://dx.doi.org/10.21037/qims-20-902

\footnotetext{
$\wedge$ ORCID: 0000-0001-6506-1267.
} 


\section{Introduction}

Fatty infiltration and iron overload commonly occur together in diffuse liver diseases, including chronic hepatitis, hemochromatosis, and fatty liver disease $(1,2)$. Hepatic iron and fat play a synergistic role in promoting disease progression $(3,4)$. The oxidative stress induced by iron in hepatocytes contributes to liver cirrhosis and promotes hepatocellular carcinoma development $(5,6)$. Fat accumulation may progress beyond simple steatosis to steatohepatitis, and cirrhosis, accelerating the fibrosis stimulus caused by iron overload $(4,7)$. Therefore, simultaneous quantification of hepatic iron and fat concentrations is important for patient management.

Physiochemical analysis of liver iron concentration (LIC) and histological examination of the fat fraction (Fat- $\left.{ }_{\text {ref }}\right)$ in a liver biopsy is the reference standards for determining hepatic iron and fat concentration $(8,9)$. However, liver biopsy is invasive, with complication rates ranging from $6 \%$ to $18 \%$ and a major complication rate of $0.1 \%(10,11)$. Minimizing complications using fine $22 \mathrm{G}$ needles and a limited number of punctures increases the risk of sampling error and accurate pathological analysis difficulty. Therefore, noninvasive iron and fat quantification methods that can evaluate the entire liver are of increasing clinical interest.

A dedicated practical guide to quantifying hepatic iron with magnetic resonance imaging (MRI) was published recently (12). The multi-echo technique measured iron and fat concentrations (13) simultaneously. However, the interaction between hepatic iron and fat may not be perfectly corrected even with six echoes, especially with severe iron deposition, spoiling the signal in later echoes $(14,15)$. Liver MRI may also be affected by fibrosis and inflammation, which affects the T2*-weighted imaging (13). Moreover, MRI is costly, with limited availability, and may also be contraindicated in patients with incompatible implants.

Computed tomography (CT) attenuation measures fatty infiltration (decreased liver attenuation) and iron overload (increased liver attenuation), but when fat and iron coexist, standard CT attenuation no longer works $(16,17)$. Dual-energy CT (DECT)-based material decomposition measured the liver's fatty composition even in the presence of iron and iodine in a phantom study (18). Another in vitro phantom study showed that DECT could measure hepatic iron without confounding from coexisting fat (19).

Although DECT-based material decomposition shows promise in measuring hepatic iron and fat, the in vivo interference from coexisting iron and fat has only been evaluated in phantom studies. We aimed to assess the in vivo accuracy of measuring coexisting hepatic iron/fat using a DECT-based three-material (fat, soft tissue and iron) decomposition algorithm in a rabbit model.

\section{Methods}

\section{Animal model}

Experiments were performed under a project license (2018KY-056) granted by the institutional ethics board of Northern Jiangsu People's Hospital, in compliance with institutional guidelines for the care and use of animals. We divided 68 8-week-old male New Zealand rabbits, each weighing approximately $1,800 \mathrm{~g}$, into the main group $(\mathrm{n}=48)$ and a validation group $(\mathrm{n}=20)$.

The main group was further divided into four equal groups $(n=12)$. Group M1 was fed a standard diet for 2 weeks and used as the normal liver group. To induce different fatty liver stages, groups M2, 3 and 4 were fed a high-fat/cholesterol diet (standard diet $+10 \%$ triglycerides $+2 \%$ cholesterol) for 2, 4, and 8 weeks, respectively (20). Iron overload was induced by intravenous injection of iron dextran $(100 \mathrm{mg} \mathrm{Fe} / \mathrm{mL})$ during the feeding and 1-2 weeks before DECT (9). Based on our preliminary experimental results, a series of total iron injection doses of $0,200,800$, 1,200, and 2,400 $\mathrm{mg}$ Fe were used (9). The $200 \mathrm{mg}$ Fe dose was given as a single injection. The $800,1,200$, and 2,400 $\mathrm{mg} \mathrm{Fe}$ doses were administered as 2, 3, and 6 injections on successive days. In each main group of 12 rabbits, 2 rabbits were administered each iron dose, and the remaining 2 rabbits were used as a backup for rabbits dying during the protocol. If less than 2 rabbits died in the main group of 12 rabbits, the extra rabbit(s) received the maximum total iron dose $(2,400 \mathrm{mg} \mathrm{Fe})$.

The validation group of 20 rabbits was divided into 4 equal groups $(\mathrm{n}=5)$. Group $\mathrm{V} 1$ was fed a standard diet for 2 weeks. Groups V2, 3 and 4 were fed a high-fat/cholesterol diet for 2, 4, and 8 weeks, respectively. A series of total iron injection doses of $0,200,800,1,200$, and 2,400 $\mathrm{mg} \mathrm{Fe}$ were administered in each validation group (one rabbit for each dose point). The different treatment of rabbits from different groups is outlined in Figure 1.

All rabbits were housed in independent cages at room temperature $\left(21 \pm 2{ }^{\circ} \mathrm{C}\right)$, with unlimited access to water and a 12-hour diurnal light cycle. The chow's weight 


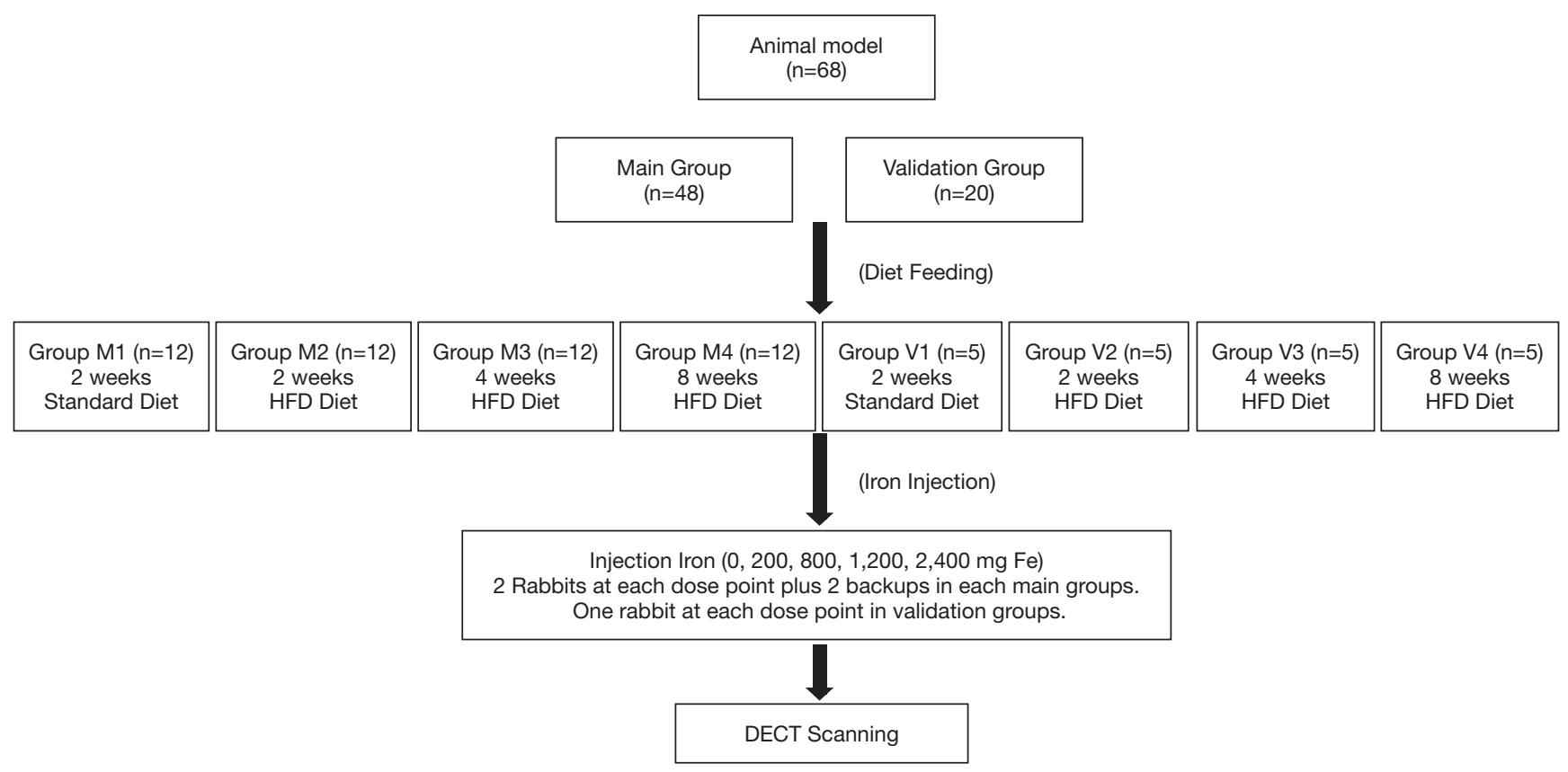

Figure 1 Flowchart of building hepatic iron and fat coexisting rabbit model. DECT, dual-energy CT; HFD, high-fat diet.

was restricted to $100 \mathrm{~g} / \mathrm{rabbit}$ per day and was entirely consumed by every rabbit each day. All rabbits underwent CT scanning within 5 days after the final iron injection. If rabbits were showing signs of poor condition, euthanasia was performed shortly after DECT scanning.

\section{Image acquisition}

Abdominal dual-source DECT (Somatom Definition Flash, Siemens AG, Forchheim, Germany) was performed following anesthetization with intravenous pentobarbital sodium $(30 \mathrm{mg} / \mathrm{kg})$. An abdominal belt was used to reduce breathing motion artifact. Upper abdominal unenhanced DECT was performed at $80 \mathrm{kVp}$ and Sn $140 \mathrm{kVp}$. The corresponding tube current was 350 and $150 \mathrm{~mA}$, respectively. Other scan parameters were as follows: detector collimation, $64 \times 0.625 \mathrm{~mm}$, gantry rotation time, $0.5 \mathrm{~s}$, pitch, 0.6 . The matrix was $512 \times 512$, and the field of view was $180 \times 180 \mathrm{~mm}$. The reconstruction kernel was D30f. CT images were reconstructed with $3-\mathrm{mm}$ slice thickness and $1.5-\mathrm{mm}$ slice interval. The volumetric CT dose index for this setting was $13.1 \mathrm{mGy}$.

\section{Image analysis}

Decomposition of hepatic iron/fat was performed using prototype software (eXamine, Siemens Medical Solutions, Forchheim, Germany v.1.0.1.33619). An iron-specific slope value of 1.9 was used to preset the iron/fat decomposition algorithm (9). The algorithm fits data using CT attenuations at $80 \mathrm{kVp}$ and $S n 140 \mathrm{kVp}$ and then calculates iron, fat, and soft tissue fractions. The decomposition algorithm's basic principle is that iron, fat, and soft tissue have unique attenuation characteristics when exposed to different $\mathrm{X}$-ray energies. Each material has its atomic number (Z), exhibiting unique binding energy (K-edge) in the photoelectric interaction with $\mathrm{X}$-rays. Elements with unique $\mathrm{K}$-edge values show different attenuations at different energy levels. Those with a high atomic number, such as iron, attenuate a greater portion with low-kilovolt than high-kilovolt photons due to the photoelectric effect (21). For a combination of two or more substances with known attenuation characteristics present in a certain ratio, DECT-based material decomposition is capable of materials separation (21). Based on this principle, the iron/fat decomposition algorithm can generate a material quantification map. The DECT virtual iron parameter (i.e., the CT attenuation values attributed to iron, termed Iron- ${ }_{\mathrm{CT}}$ ) was obtained from three regions of interest (ROI) on the material quantification maps. The fat fraction (Fat- ${ }_{\mathrm{CT}}$ ) was obtained within the same ROIs. The units of Iron- ${ }_{\mathrm{CT}}$ are given in Hounsfield units (HU), and the units of Fat ${ }^{-}{ }_{\mathrm{CT}}$ 

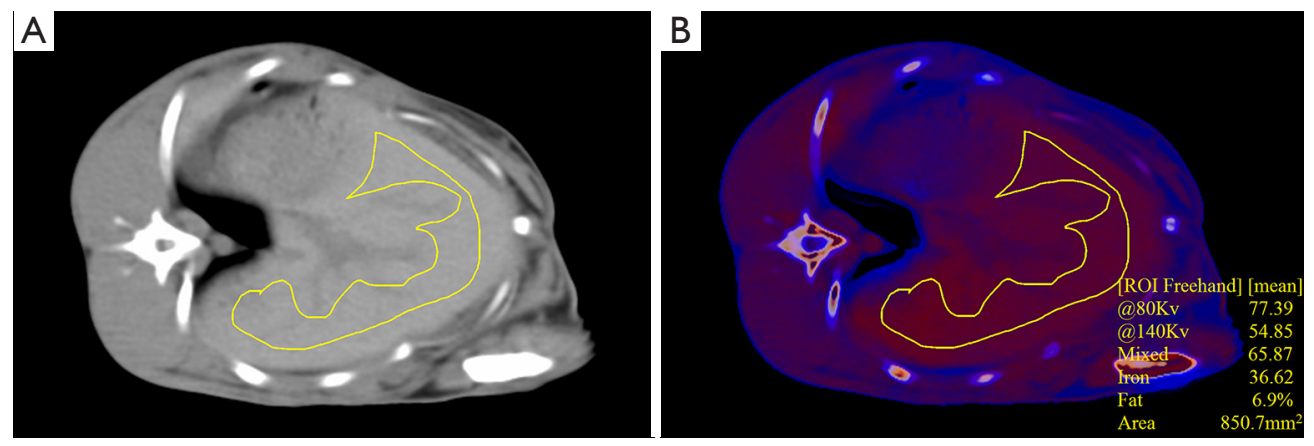

Figure 2 Example of region of interest (ROI) on liver parenchyma simultaneously measuring iron and fat on the iron/fat decomposition material map. (A) Free hand ROI drawn on the Mixed image, excluding vessels and bile duct and $5 \mathrm{~mm}$ from the liver border. (B) Iron/fat

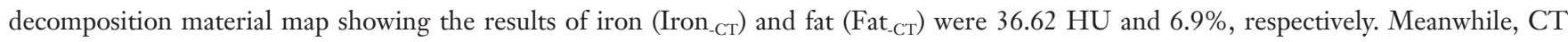
attenuation of the same ROI on $80 \mathrm{kVp}$, Sn140 kVp and Mixed images were also obtained. CT, computed tomography; HU, Hounsfield units.

are given in percentage (\%). Also, CT attenuation at $80 \mathrm{kVp}$, Sn $140 \mathrm{kVp}$, and Mixed (ratio 80:Sn140 kVp, 0.5:0.5) was obtained from the same ROIs.

The liver DECT images were analyzed independently by two radiologists (each with $>5$ years of experience in abdominal imaging), blinded to the diet and iron treatments and the histopathology and spectroscopy results. Three freehand ROIs with an area of $800-1,800 \mathrm{~mm}^{2}$ were drawn on Mixed images approximately $5 \mathrm{~mm}$ from the liver boundary on three consecutive slices, which showed the largest area of liver parenchyma. The main vessels and bile ducts were also carefully avoided with a distance apart $\geq 5 \mathrm{~mm}$. These three ROIs were copied to the iron/fat decomposition material maps. The Iron- ${ }_{\mathrm{CT}}(\mathrm{HU})$, Fat- ${ }_{\mathrm{CT}}$ (\%), and the mean CT attenuation at $80 \mathrm{kVp}, \mathrm{Sn} 140 \mathrm{kVp}$, and Mixed were obtained from each ROI. The mean value from the three ROIs were used for further analysis. A representative ROI on the Mixed and material maps is presented in Figure 2.

\section{Patbological and spectroscopic analyses}

After CT scanning, all rabbits were humanely killed by pentobarbital overdose to obtain liver samples. Because the iron and fat distribution were diffusely uniform throughout the entire liver in our preliminary experiments $(9,20)$, tissue specimens ( 3 pieces, each about $5 \mathrm{~g}$ wet weight) were obtained from the medial left liver lobe for spectroscopic analysis. An additional specimen was obtained and then formalin-fixed paraffin-embedded for hematoxylin and eosin (H\&E) and Prussian blue staining.
Pathological fat content was measured on H\&Estained preparations by one pathologist (11 years of clinical experience conducting hepatic pathologic examinations), blinded to the CT measurements. Using a computerized quantitative analysis software programmed in Image $\mathbf{J}$ (v1.48, National Institutes of Health USA), the fat fraction (Fat-ref) was quantitatively assessed as the percentage of the volume of fat vacuoles over the total volume of hepatocytes. Steatosis was graded using standard criteria: normal $(\leq 5 \%)$, mild (5-33\%), moderate (33-66\%), and severe (>66\%) (20).

For hepatic iron quantification, inductively-coupled plasma spectroscopy (ICP; Hitachi, Ltd., Tokyo, Japan) was used (22). Dried liver samples were ashed and dissolved in hydrochloric acid. The spectrometer measured the iron concentration as ferric ions in the solution. Finally, the LIC (mg Fe/g dry weight liver tissue) was calculated. Based on the optimal spectroscopic agreement from the three samples, the average was used for analysis. The level of iron was graded as: normal, <1.8 mg Fe/g $(32 \mu \mathrm{mol} / \mathrm{g})$; mild overload, $1.8-3.2 \mathrm{mg} \mathrm{Fe} / \mathrm{g}(32-57 \mu \mathrm{mol} / \mathrm{g})$; moderate overload, 3.2-7.0 mg Fe/g (57-126 $\mu \mathrm{mol} / \mathrm{g})$; severe overload, 7.0-15 mg Fe/g (126-270 $\mu \mathrm{mol} / \mathrm{g})$; and massive iron overload $>15.0 \mathrm{mg} \mathrm{Fe} / \mathrm{g}(270 \mu \mathrm{mol} / \mathrm{g})(23)$.

\section{Statistical analysis}

All the statistical analyses were performed on SPSS software (version 19.0; Chicago, IL, USA) or GraphPad Prism (GraphPad v.5.01, San Diego, CA, USA). The ShapiroWilk test tested all parameters to determine normality. The variables are described as the mean \pm standard deviations. 
$\mathrm{P}<0.05$ was considered to indicate a significant difference. The inter-rater reliability between measurements from two readers was tested by intraclass correlation coefficients (ICCs). An ICC of 0.8-1.00 was considered to indicate excellent agreement. DECT measurements were averaged for further analyses if the excellent agreement was obtained.

The correlations between the DECT parameters in the main group (Iron ${ }_{\mathrm{CT}}$, Fat $^{-}{ }_{\mathrm{CT}}$, and $\mathrm{CT}$ attenuation at $80 \mathrm{kVp}$, Sn140 kVp, Mixed) and the reference values of LIC and Fat- ${ }_{\text {ref }}$ were statistically analyzed by Pearson correlationbased Gaussian distribution of DECT parameters. The linear regression equations for calculating the Iron- ${ }_{\mathrm{CT}^{-}}$ derived LIC (LIC- $\left.{ }_{\mathrm{CT}}\right)$ and $\mathrm{Fat}_{-\mathrm{CT}^{-}}$-derived fat $\left(\mathrm{FF}_{-\mathrm{CT}}\right)$ fractions were built using the main group data. Data from the validation group were used to validate the accuracy of the established equations. The Bland-Altman analysis was used to determine agreements between the Iron- ${ }_{\mathrm{CT}^{T}}$-derived LIC (LIC- ${ }_{\mathrm{CT}}$ ) and the ICP-derived LIC (LIC- ${ }_{\text {ICP }}$ ), as well as the Fat ${ }^{-}{ }_{\mathrm{CT}}$-derived fat fraction $\left(\mathrm{FF}_{-\mathrm{CT}}\right)$ and histological fat fraction (Fat- ${ }_{\text {ref }}$ ).

To assess the interference of fat on iron quantification, the linear regression lines between Iron- ${ }_{\mathrm{CT}}$ and LIC were compared by analysis of covariance among the normal fat content, mild, moderate, and severe steatosis groups (the moderate and severe steatosis rabbits were combined into one group because only one case of severe steatosis was obtained). To determine the interference of iron on fat quantification, the regression lines between $\mathrm{Fat}^{-{ }_{\mathrm{CT}}}$ and $\mathrm{Fat}^{-}{ }_{\text {ref }}$ were compared among the normal iron content and the mild, moderate, severe, and massive iron overload groups.

\section{Results}

\section{Hepatic iron and fat coexisting models}

Among the 68 rabbits, 79\% (38/48) in the main group and $80 \%(16 / 20)$ in the validation group survived and underwent DECT scanning. Six rabbits died following iron injections but before completing all of the iron injections. Eight rabbits, comprising 1 rabbit at 5 weeks, 2 rabbits at 6 weeks, and 5 rabbits at 7 weeks of high-fat/cholesterol diet, died before any iron injection. Examples of iron accumulation only, fat accumulation only, and iron/fat coexisting rabbits are shown in Figure 3.

The fat fraction determined by histopathology (Fat-ref) of the 38 rabbits in the main group ranged from $0.5 \%$ to $68.3 \%$. According to the fat fraction grading criterion, there were 12 rabbits with normal fat liver levels, 12 with mild steatosis, 13 with moderate steatosis, and 1 with severe steatosis, in which the average fat fraction was $3.0 \% \pm 1.2 \%$, $15.6 \% \pm 5.4 \%, 43.8 \% \pm 8.9 \%$ and $68.3 \%$, respectively.

LIC determined by spectroscopy ranged from 0.25 to $27.9 \mathrm{mg} / \mathrm{g}(4.5-502.2 \mu \mathrm{mol} / \mathrm{g})$. According to the liver iron grading criterion, there were 7 rabbits with normal liver iron, 7 with mild iron overload, 8 with moderate iron overload, 9 with severe iron overload, and 7 with massive iron overload, in which the average LIC was $0.96 \pm 0.52 \mathrm{mg} \mathrm{Fe} / \mathrm{g}(17.28$ $\pm 9.36 \mu \mathrm{mol} / \mathrm{g}), 2.31 \pm 0.47 \mathrm{Fe} \mathrm{mg} / \mathrm{g}(41.58 \pm 8.46 \mu \mathrm{mol} / \mathrm{g})$, $5.19 \pm 1.48 \mathrm{mg} \mathrm{Fe} / \mathrm{g}(93.42 \pm 26.64 \mu \mathrm{mol} / \mathrm{g}), 9.40 \pm 1.30 \mathrm{mg} \mathrm{Fe} / \mathrm{g}$ $(169.2 \pm 23.4 \mu \mathrm{mol} / \mathrm{g})$, and $20.46 \pm 4.57 \mathrm{mg} \mathrm{Fe} / \mathrm{g}(368.28$ $\pm 82.26 \mu \mathrm{mol} / \mathrm{g}$ ), respectively. The details of iron and fat grading are listed in Table 1.

\section{DECT measurements of iron and fat decomposition}

The ICCs between the two observers showed excellent agreement for all DECT parameters: Iron- ${ }_{\mathrm{CT}}(0.993)$, Fat- ${ }_{\mathrm{CT}}$ (0.985), $80 \mathrm{kVp}$ (0.998), Sn140 kVp (0.994), and Mixed (0.998). The mean value of the two observers was used for further analysis. The CT measurements from all 38 main group rabbits are listed in Tables 2 and 3 .

\section{Correlation between DECT measurements and iron/fat reference}

The Iron- ${ }_{\mathrm{CT}}$ strongly and positively correlated with the LIC $(r=0.94, P<0.001)$, but there were no significant correlations between Fat ${ }_{\text {CT }}$ and LIC $(\mathrm{r}=-0.15, \mathrm{P}=0.356)$. The linear regression equation for LIC ( $\mathrm{mg} \mathrm{Fe} / \mathrm{g}$ ) calculated from Iron- ${ }_{\mathrm{CT}}$ was:

$$
Y=0.3278 X-1.522 \quad(\mathrm{P}<0.001)
$$

where $\mathrm{X}$ indicates the $\mathrm{HU}$ of Iron- ${ }_{\mathrm{CT}}$, and $\mathrm{Y}$ represents $\mathrm{LIC}^{-}{ }_{\mathrm{CT}}$ in units of $\mathrm{mg} \mathrm{Fe} / \mathrm{g}$ (Figure 4A). Hepatic CT attenuation at $80 \mathrm{kVp}, \mathrm{Sn} 140 \mathrm{kVp}$ and Mixed also positively correlated with the LIC ( $\mathrm{r}=0.81,0.51,0.71$, respectively; $\mathrm{P}<0.05)$.

The Fat ${ }_{\text {ст }}$ positively correlated with $\mathrm{Fat}^{-}{ }_{\text {ref }}(\mathrm{r}=0.88$, $\mathrm{P}<0.001)$, but there were no significant correlations between Iron- $_{\mathrm{CT}}$ and $\mathrm{Fat}{ }_{\text {ref }}(\mathrm{r}=-0.22, \mathrm{P}=0.176)$. The linear regression equation for the fat fraction corrected from Fat ${ }^{-}{ }_{\mathrm{CT}}$ was:

$$
Y=1.705 X+13.65 \quad(\mathrm{P}<0.001)
$$

where $\mathrm{X}$ indicates Fat $^{-}{ }_{\mathrm{CT}}$ (fat percentage measured on DECT material maps), and Y represents FF-CT (fat percentage corrected from pathological fat fraction) (Figure $4 B$ ). Hepatic CT attenuation on $80 \mathrm{kVp}$, Sn140 kVp and Mixed 


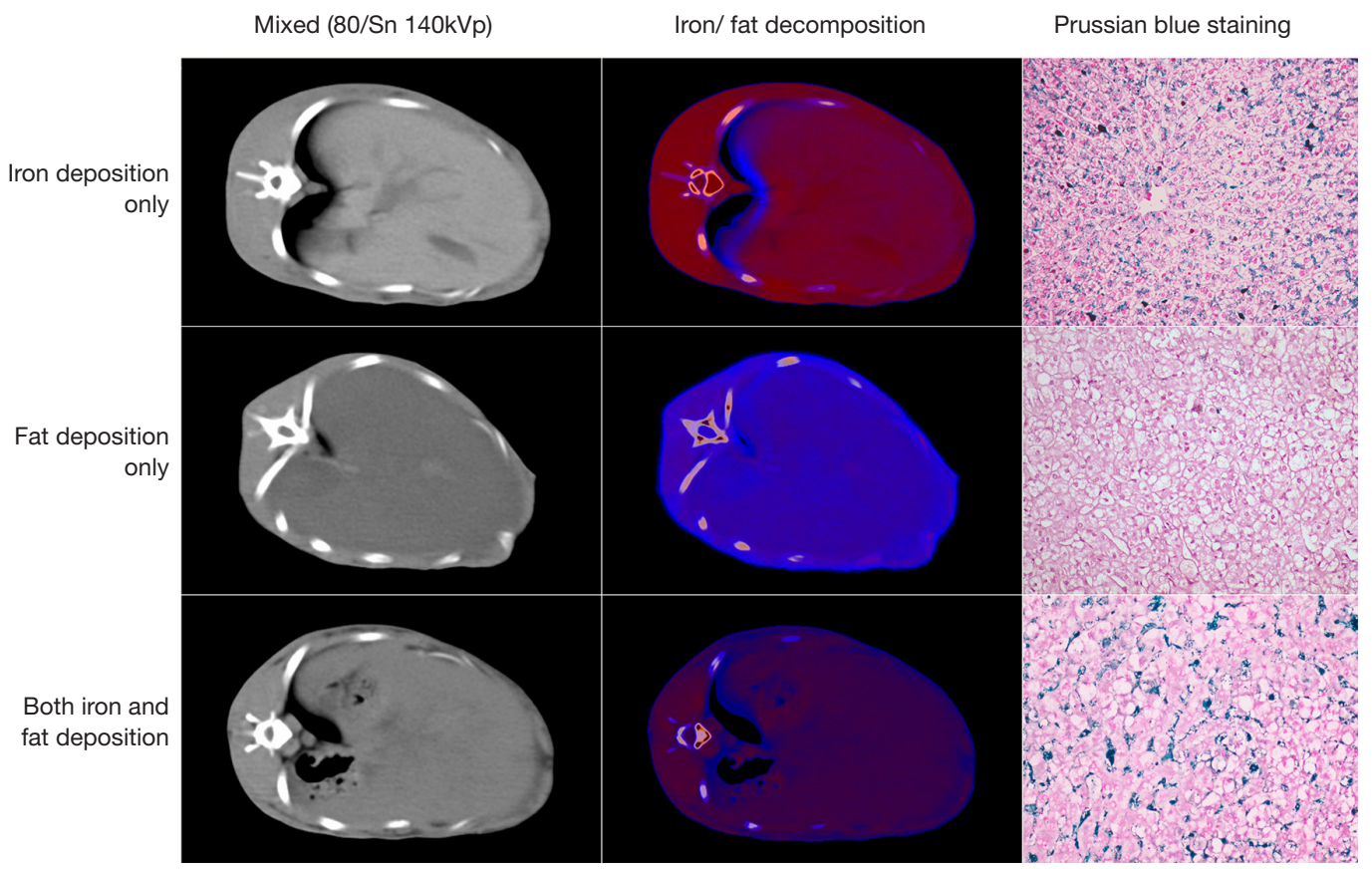

Figure 3 Rabbit model of iron deposition only (top row), fat deposition only (middle row), and both iron and fat deposition (bottom row) with Mixed (80/Sn140 kVp images) (first column), iron/fat decomposition images (second column) and histopathological Prussian blue staining at $\times 200$ (third column). The LIC from top to bottom rows was 10.28, 3.88, and 5.39 mg Fe/g (185.04, 69.84, 97.02 $\mu \mathrm{mol} /$ g), respectively. The fat fraction (Fat-ref) was $2.6 \%, 60.3 \%$ and $68.3 \%$, respectively. The corresponding DECT measurements of Iron $-\mathrm{CT}$ were $30.54 \mathrm{HU}, 2.85 \mathrm{HU}, 16.05 \mathrm{HU}$, and Fat ${ }_{-\mathrm{CT}}$ of 2.8\%, 21.6\%, 25.1\%, respectively. DECT, dual-energy computed tomography; HU, Hounsfield units; LIC, liver iron content.

Table 1 Different levels of coexisting hepatic iron and fat in a rabbit model $(\mathrm{n}=38)$

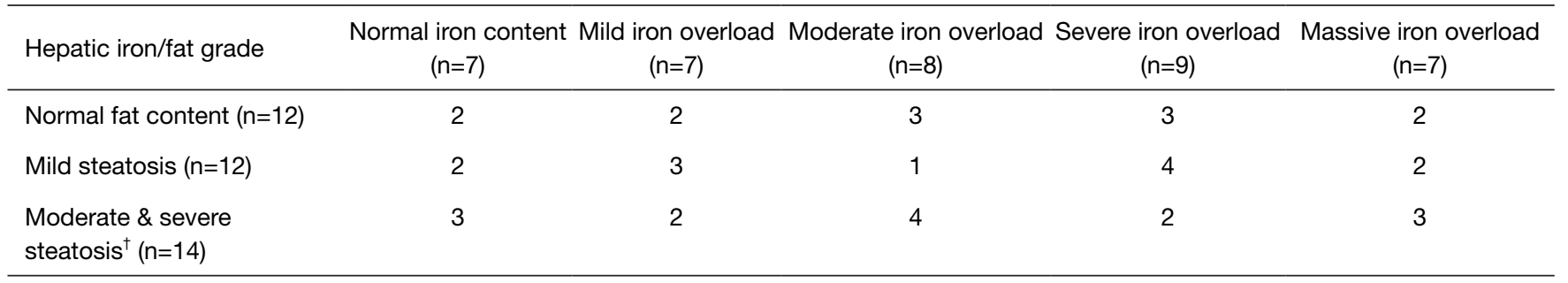

$\dagger$, as there was only one rabbit with severe steatosis, the moderate and severe steatosis groups were combined.

negatively correlated with Fat ${ }_{\text {ref }}(\mathrm{r}=-0.63,-0.84,-0.72$, respectively; $\mathrm{P}<0.05)$.

\section{Validation of the iron/fat regression equations}

The accuracy of Eqs. [1 and 2] for LIC and fat fraction quantification was validated in a group of 16 rabbits loaded with different iron/fat levels. The mean LIC- ${ }_{\mathrm{CT}}$ obtained using equation 1 was $8.8 \pm 1.9 \mathrm{mg} \mathrm{Fe} / \mathrm{g}(158.4 \pm 34.2 \mu \mathrm{mol} / \mathrm{g})$ dry tissue. The postmortem LIC- ${ }_{\text {ICP }}$ measured with ICP was $9.3 \pm 2.1 \mathrm{mg} \mathrm{Fe} / \mathrm{g}(167.4 \pm 37.8 \mu \mathrm{mol} / \mathrm{g})$ dry tissue. Bland-Altman analysis between $\mathrm{LIC}_{-\mathrm{CT}}$ and LIC- ${ }_{\text {ICP }}$ showed a mean difference of $0.95 \mathrm{mg} \mathrm{Fe} / \mathrm{g}(17.1 \mu \mathrm{mol} / \mathrm{g})$ with a $95 \%$ confidence interval (CI, -4.4-5.3 $\mathrm{mg} \mathrm{Fe} / \mathrm{g}$ (-79.2-95.4 $\mu \mathrm{mol} / \mathrm{g})$. However, no significant difference was found between $\mathrm{LIC}_{-\mathrm{CT}}$ and $\mathrm{LIC}_{-\mathrm{ICP}}(\mathrm{P}>0.05)$ (Figure $5 A$ ). The mean FF(CT) obtained using equation 2 was $18.1 \% \pm 4.1 \%$. The histological fat fraction $\left(\mathrm{Fat}_{-}{ }_{\text {ref }}\right.$ ) was $19.5 \% \pm 4.2 \%$. Bland-Altman analysis between Fat Fraction (CT) and histological fat fraction showed a mean difference 
Table 2 DECT measurements compared with iron/fat reference with different levels of hepatic iron content $(n=38)$

\begin{tabular}{|c|c|c|c|c|c|}
\hline $\begin{array}{l}\text { DECT measurements } \\
\text { and references }\end{array}$ & $\begin{array}{l}\text { Normal iron content } \\
\qquad(\mathrm{n}=7)\end{array}$ & $\begin{array}{l}\text { Mild iron overload } \\
\qquad(\mathrm{n}=7)\end{array}$ & $\begin{array}{l}\text { Moderate iron overload } \\
\qquad(\mathrm{n}=8)\end{array}$ & $\begin{array}{l}\text { Severe iron overload } \\
\qquad(n=9)\end{array}$ & $\begin{array}{l}\text { Massive iron overload } \\
\qquad(\mathrm{n}=7)\end{array}$ \\
\hline Iron- $_{\text {CT }}(\mathrm{HU})$ & $5.81 \pm 6.77$ & $12.75 \pm 3.91$ & $21.25 \pm 3.41$ & $37.86 \pm 7.88$ & $61.05 \pm 11.60$ \\
\hline 80 kVp (HU) & $47.53 \pm 21.61$ & $57.46 \pm 14.69$ & $65.14 \pm 16.87$ & $82.60 \pm 9.08$ & $102.96 \pm 16.46$ \\
\hline Sn140 kVp (HU) & $43.91 \pm 19.48$ & $49.69 \pm 14.28$ & $51.82 \pm 16.73$ & $59.79 \pm 7.72$ & $65.26 \pm 10.83$ \\
\hline LIC $(\mathrm{mg} / \mathrm{g}) /(\mu \mathrm{mol} / \mathrm{g})$ & $\begin{array}{c}0.96 \pm 0.52 \\
(17.28 \pm 9.36)\end{array}$ & $\begin{array}{c}2.31 \pm 0.47 \\
(41.58 \pm 8.46)\end{array}$ & $\begin{array}{c}5.19 \pm 1.48 \\
(93.42 \pm 26.64)\end{array}$ & $\begin{array}{c}9.40 \pm 1.30 \\
(169.2 \pm 23.4)\end{array}$ & $\begin{array}{c}20.46 \pm 4.57 \\
(368.28 \pm 82.26)\end{array}$ \\
\hline Fat- ${ }_{\text {ref }}(\%)$ & $28.9 \pm 23.9$ & $21.6 \pm 21.6$ & $25.8 \pm 24.0$ & $16 . \pm 12.8$ & $22.1 \pm 18.8$ \\
\hline
\end{tabular}

DECT, dual-energy CT; HU, Hounsfield units; LIC, liver iron content.

Table 3 DECT measurements with iron/fat reference with different levels of hepatic fat $(\mathrm{n}=38)$

\begin{tabular}{lccc}
\hline DECT measurements and references & Normal fat content $(\mathrm{n}=12)$ & Mild steatosis $(\mathrm{n}=12)$ & Moderate \& severe steatosis $(\mathrm{n}=14)$ \\
\hline Iron- $_{\text {CT }}(\mathrm{HU})$ & $29.28 \pm 24.41$ & $31.03 \pm 17.25$ & $24.59 \pm 20.74$ \\
Fat- ${ }_{\mathrm{cT}}(\%)$ & $-6.1 \pm 5.5$ & $5.9 \pm 5.4$ & $14.5 \pm 6.1$ \\
$80 \mathrm{kVp}(\mathrm{HU})$ & $86.68 \pm 19.71$ & $73.30 \pm 19.71$ & $57.18 \pm 24.68$ \\
Sn140 kVp $(\mathrm{HU})$ & $69.10 \pm 7.28$ & $54.39 \pm 10.15$ & $41.64 \pm 12.76$ \\
Mixed $(\mathrm{HU})$ & $77.64 \pm 12.87$ & $63.59 \pm 14.73$ & $49.18 \pm 18.57$ \\
LIC $(\mathrm{mg} / \mathrm{g}) /(\mu \mathrm{mol} / \mathrm{g})$ & $8.23 \pm 8.42(148.14 \pm 151.56)$ & $7.97 \pm 7.11(143.46 \pm 127.98)$ & $6.99 \pm 6.48(125.82 \pm 116.64)$ \\
Fat ${ }_{\text {ref }}(\%)$ & $2.3 \pm 1.2$ & $15.6 \pm 5.4$ & $45.5 \pm 10.8$ \\
\hline
\end{tabular}

DECT, dual-energy CT; HU, Hounsfield Units; LIC, liver iron content.
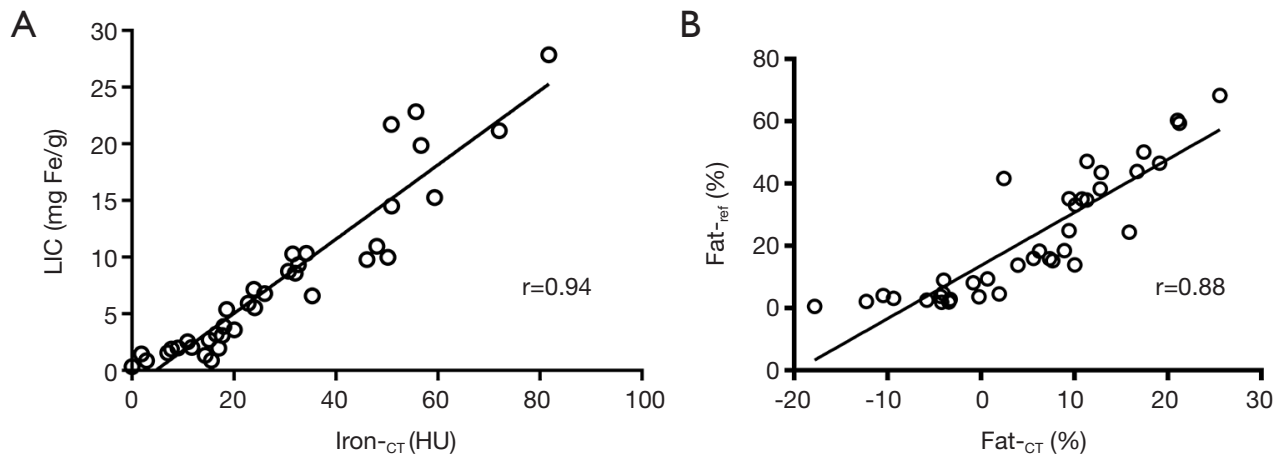

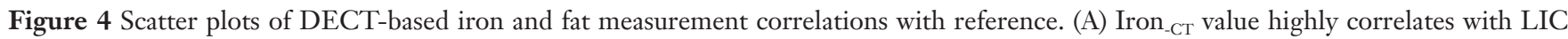

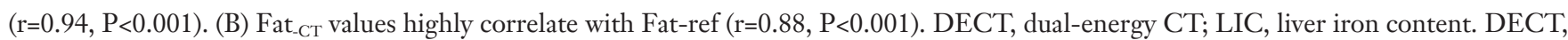
dual-energy computed tomography; LIC, liver iron content. 

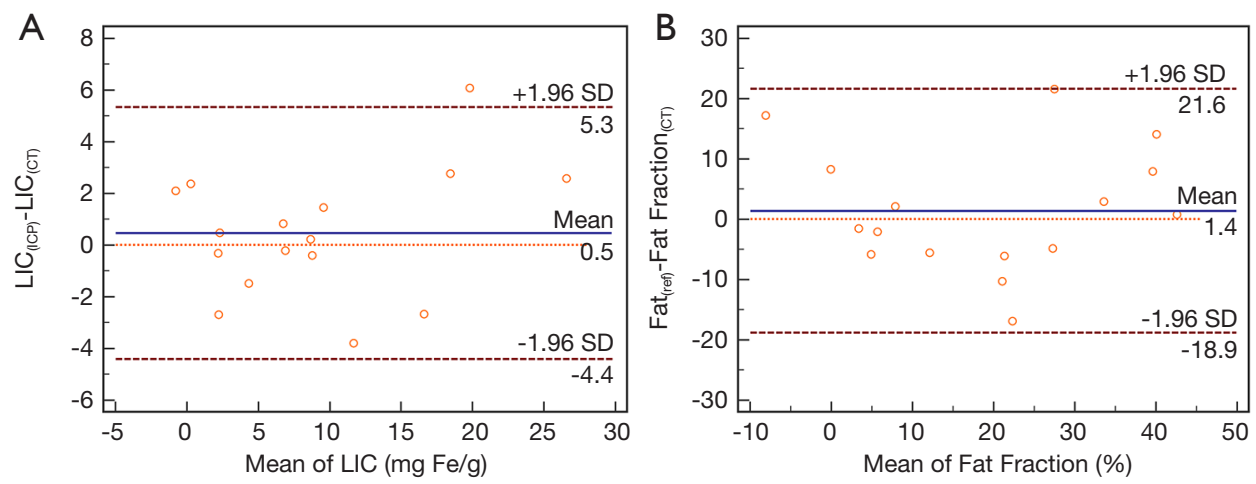

Figure 5 Bland-Altman plots showing agreement of DECT-derived iron/fat measurements with the references. The mean difference was $0.5 \mathrm{mg} \mathrm{Fe} / \mathrm{g}(9 \mu \mathrm{mol} / \mathrm{g})$ for iron (A) and 1.4\% for fat fraction (B) but was not statistically significant $(\mathrm{P}>0.05)$. The solid line shows the mean difference between the two methods, and the dashed lines indicate the upper and lower 95\% bounds of agreement between them. DECT, dual-energy computed tomography; ICP, inductively-coupled plasma spectroscopy; LIC, liver iron content; SD, standard error.
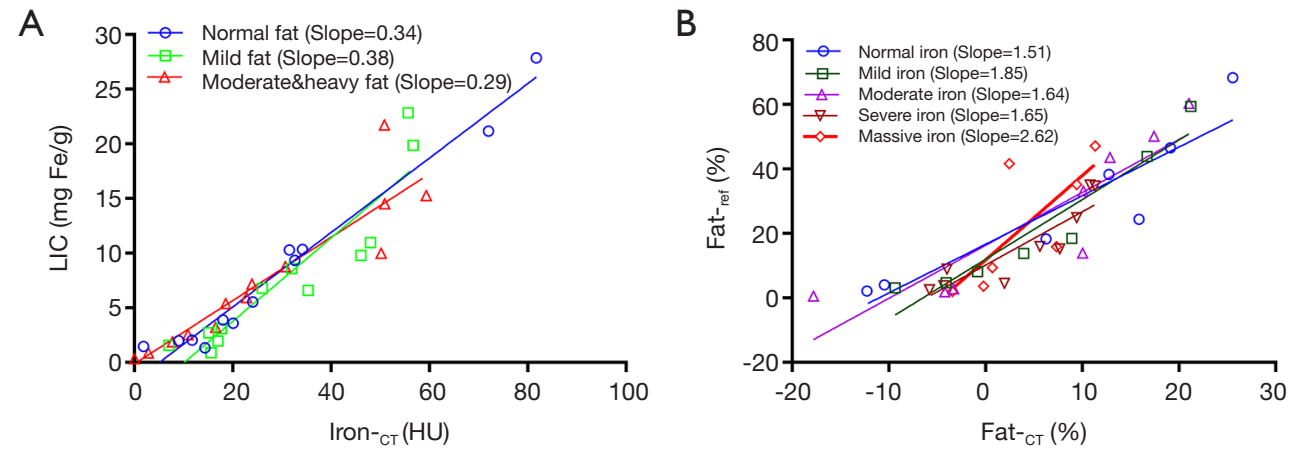

Figure 6 Scatter plots of iron quantification linear regression lines at three different fatty liver levels (A) and fat quantification linear regression lines at five hepatic iron levels (B). The slopes from the three fat levels in iron quantification show no significant difference. The slope from massive iron overload in fat quantification was lower than the slopes from other iron levels, showing that fat was underestimated at massive levels of iron [>15.0 mg Fe/g $(270 \mu \mathrm{mol} / \mathrm{g})]$. LIC, liver iron content.

of $1.4 \%$ (95\% CI, -18.9-21.6\%). However, no significant difference was found between the mean Fat Fraction (CT) and a histological fat fraction $(\mathrm{P}>0.05)$ (Figure $5 B)$.

\section{Effect of fat on iron quantification and iron on fat quantification}

For iron quantification, the linear equations between Iron- $_{\mathrm{CT}}(\mathrm{X})$ and LIC $(\mathrm{Y})$ at three levels of Fat- ${ }_{\text {ref }}$ were built separately (Table S1). Iron- ${ }_{\mathrm{CT}}$ and LIC were highly positively correlated at each fatty level (Figure $6 A$ ). Analysis of covariance showed that slopes for normal (0.34), mild (0.38), and moderate and severe steatosis (0.29) had no significant difference $(\mathrm{F}=1.933, \mathrm{P}=0.161)$, indicating that fat had no significant influence on iron measurements.
For fat quantification, linear correlation equations between Fat- ${ }_{\mathrm{CT}}(\mathrm{X})$ and Fat $^{-}{ }_{\text {ref }}(\mathrm{Y})$ at five different levels of LIC were built separately (Table S2). Fat- ${ }_{\text {Ст }}$ and Fat- ${ }_{\text {ref }}$ were highly positively correlated at each level of iron (Figure $6 B$ ). The covariance analysis showed that slopes for normal iron content and mild, moderate, severe iron overload had no significant differences $(\mathrm{F}=0.178, \mathrm{P}=0.910)$. However, the massive iron overload group had a larger slope than the normal iron content group ( $\mathrm{F}=5.502, \mathrm{P}=0.041)$, indicating that massive iron deposition leads to underestimating Fat $^{-}{ }_{\mathrm{CT}}$.

\section{Discussion}

The competing effects of increased CT attenuation from iron and decreased CT attenuation from fat normally make 
iron/fat quantification by CT unreliable when both are present. The present data from 68 rabbits on high-fat diets with iron injections to simulate various combinations of iron overload and fatty liver demonstrate that the DECT iron/fat decomposition accurately measured liver iron and fat content compared with spectroscopy histopathology. Both Iron- ${ }_{\text {Ст }}$ and Fat- ${ }_{\text {Ст }}$ obtained by DECT iron/ fat decomposition highly correlated with the reference standards, when both were present, the relationship breaking down only in the setting of massive iron overload. Iron- $_{\text {Ст }}$ measured hepatic iron accurately even with moderate steatosis and in the single rabbit that survived severe steatosis. Fat ${ }_{\mathrm{CT}}$ accurately measured fat fraction at normal to severe iron overload levels. With massive iron overload, fat was underestimated by Fat- ${ }_{\mathrm{CT}}$.

Conventional CT assesses hepatic iron overload or fat accumulation by showing increased or decreased hepatic CT attenuation. Our study showed that CT values at $80 \mathrm{kVp}, \mathrm{Sn} 140 \mathrm{kVp}$ and Mixed positively correlated with LIC and negatively with Fat- $_{- \text {ref, }}$ as expected. However, CT attenuation measurements are not accurate when both fat and iron are present. Compared with conventional CT, the DECT-based iron/fat decomposition technique obtained Iron- $_{\mathrm{CT}}$ and Fat ${ }_{\mathrm{CT}}$ values showing a strong correlation with the corresponding references and the spectroscopic and histopathologic findings. These advantages of material decomposition are only possible with DECT. Using dual $\mathrm{X}$-ray tubes and detectors, DECT simultaneously acquires data with two different tube voltages, allowing for material separation with comparable atomic numbers according to the differences in the photoelectric and Compton effects of CT attenuation at different energies (24). For iron quantification, rabbit and patient studies indicate an iron-specific material decomposition algorithm based on DECT can quantify hepatic iron $(9,23)$. Using the same iron-specific slope of 1.9 as in a previous study (23), the correlation of Iron- ${ }_{\text {CT }}$ with LIC in our current study was 0.99 , similar to both a prior patient study (23) $(r=0.87)$ and a prior rabbit model study (9) ( $\mathrm{r}=0.98)$. For fat quantification, our study showed the correlation of Fat ${ }^{-}{ }_{\text {CT }}$ with Fat- ${ }^{\text {ref }}$ was 0.88 , which was consistent with a previous dual-source DECT phantom study $(\mathrm{r}=0.79)$ (25), indicating the role of material decomposition as a promising imaging index for quantifying hepatic fat content. All previous studies demonstrated the feasibility of DECT in separate iron or fat quantification, but our data extend this accurate characterization of hepatic fat and iron even when they are coexisting.
To evaluate the iron/fat interactions on quantification by DECT, we created a rabbit model with a wide range of simultaneous hepatic iron and fat contents, which was challenging due to the iron and fatty/cholesterol diet toxicity. Only one rabbit survived with severe steatosis plus iron, so we had to group the moderate and severe steatosis cases in our analysis. We found that Iron- ${ }_{\mathrm{CT}}$ showed a high correlation with LIC, even with the confounding effects of moderate and severe steatosis $(\mathrm{r}=0.93)$. This result was in agreement with Fisher's phantom study, in which the virtual iron content highly correlated with LIC even at a fat fraction of $50 \%(\mathrm{r}=0.96)(19)$. Comparing iron attenuation values in fat-present and fat-absent groups of rats, $\mathrm{Ma}$ et al. concluded that the DECT virtual iron content correlated with true iron content even in the presence of fat (26), but they did not derive actual liver iron values. Our results agree and further show that the DECT decomposition technique eliminates fat interference with iron quantification over a range of hepatic steatosis grades and provides accurate measurements of hepatic iron in $\mathrm{mg} \mathrm{Fe/gram} \mathrm{dry} \mathrm{weight}$ liver. Another phantom study conducted on fast-kilovoltpeak switching DECT suggested iron was overestimated in the absence of fat and underestimated in the presence of fat (27). The better discrimination between fat and iron observed in our study might be explained by the more accurate separation of low and high $\mathrm{X}$-ray energy levels with a dual-source than can be achieved with fastkilovolt switching DECT (21). Moreover, tin filtering was used with dual-source DECT in our study, which helps separate the low and high X-ray energy accurately. Another difference was our use of a 3-material (iron, fat, soft tissue) decomposition algorithm compared with the two-material (iron and water) used in the prior study (21).

Fat- ${ }_{\text {Ст }}$ positively correlated with the fat fraction even up to severe iron overload $(\mathrm{r}=0.89)$, in agreement with a previous phantom study (18). We observed a trend of increasing linear regression slopes for the relationship between Fat ${ }_{\text {СT }}$ and Fat- ${ }_{\text {ref }}$, which became significantly different with massive iron overload. This is consistent with a phantom study carried out with fast-kilovolt-peak switching DECT (15). This finding suggests that even if 3-material decomposition is more accurate than twomaterial decomposition reported in that phantom study, the iron interference on fat measurement is hard to avoid completely. Multi-material decomposition algorithms separating three or more specific materials using only two energy levels is challenging (21). More experiments and data are needed to improve this aspect. Other substances 
in the liver with atomic numbers close to the iron (e.g., copper, with similar amounts of coexisting iron and copper) may influence the decomposition.

The study had several limitations. First, because the different levels of coexisting fat and iron content in vivo were difficult to control, and especially because of the high toxicity of severe steatosis and iron overload, our study had only one rabbit survive with severe fatty liver combined with iron deposition. Further studies may be needed to explore the influence of severe fatty liver on iron quantification. Second, although DECT's accuracy for simultaneous fat and iron quantification was high in this rabbit model, patterns of iron and fat deposition in humans may differ. Third, our study only investigated whether liver iron and fat quantification interfered with each other, and other materials such as copper were not included. Moreover, to minimize the image noise, a relatively high radiation dose close to that used for humans was used for the rabbits. An automated dose reduction technique (CareDose4D, Siemens Medical Solutions) could minimize radiation exposure in a future human study. Finally, negative CT fat fractions were measured in several normal rabbits, which might due to CT attenuation being insensitive to low levels of fat decomposition. Improved software for directly measuring mild liver fat decomposition is needed.

\section{Conclusions}

DECT-based iron/fat decomposition accurately measured coexisting hepatic iron and fat concentrations over a broad range in a rabbit model. However, hepatic fat quantitation was underestimated with massive iron overload. Further confirmatory studies in humans are warranted. DECT might be a feasible alternative method for measuring hepatic iron and fat, especially in patients with MRI contraindications or severe iron accumulation.

\section{Acknowledgments}

The authors thank Dr. Yuqin Ling from the Department of Pathology, Zhongshan Hospital, Fudan University, and Mr. Li Ling from Fudan University for their support of this study.

Funding: This study was funded by Top Six Talent Summit Project of Jiangsu Province Human Resources and Social Security Department (2016-WSN-277); the Youth Project from Department of Science and Technology of Jiangsu Province (BK20160450); Jiangsu Provincial Government
Scholarship for Studying Abroad (2018); Jiangsu Provincial Youth Talents Program for Medicine (QNRC2016321); Yangzhou Municipal Youth Talents Program for Medicine (YZZDRC201816).

\section{Footnote}

Conflicts of Interest: All authors have completed the ICMJE uniform disclosure form (available at http://dx.doi. org/10.21037/qims-20-902). The authors have no conflicts of interest to declare.

Ethical Statement: Experiments were performed under a project license (2018KY-056) granted by the institutional ethics board of Northern Jiangsu People's Hospital, in compliance with institutional guidelines for the care and use of animals.

Open Access Statement: This is an Open Access article distributed in accordance with the Creative Commons Attribution-NonCommercial-NoDerivs 4.0 International License (CC BY-NC-ND 4.0), which permits the noncommercial replication and distribution of the article with the strict proviso that no changes or edits are made and the original work is properly cited (including links to both the formal publication through the relevant DOI and the license). See: https://creativecommons.org/licenses/by-nc-nd/4.0/.

\section{References}

1. Kühn JP, Meffert P, Heske C, Kromrey ML, Schmidt CO, Mensel B, Völzke H, Lerch MM, Hernando D, Mayerle J, Reeder SB. Prevalence of Fatty Liver Disease and Hepatic Iron Overload in a Northeastern German Population by Using Quantitative MR Imaging. Radiology 2017;284:706-16.

2. George DK, Goldwurm S, MacDonald GA, Cowley LL, Walker NI, Ward PJ, Jazwinska EC, Powell LW. Increased hepatic iron concentration in nonalcoholic steatohepatitis is associated with increased fibrosis. Gastroenterology 1998;114:311-8.

3. Aigner E, Theurl I, Theurl M, Lederer D, Haufe H, Dietze O, Strasser M, Datz C, Weiss G. Pathways underlying iron accumulation in human nonalcoholic fatty liver disease. Am J Clin Nutr 2008;87:1374-83.

4. Powell EE, Ali A, Clouston AD, Dixon JL, Lincoln DJ, Purdie DM, Fletcher LM, Powell LW, Jonsson JR. Steatosis is a cofactor in liver injury in hemochromatosis. 
Gastroenterology 2005;129:1937-43.

5. Kew MC. Hepatic iron overload and hepatocellular carcinoma. Liver Cancer 2014;3:31-40.

6. Harrison SA, Bacon BR. Relation of hemochromatosis with hepatocellular carcinoma: epidemiology, natural history, pathophysiology, screening, treatment, and prevention. Med Clin North Am 2005;89:391-409.

7. Bugianesi E, Leone N, Vanni E, Marchesini G, Brunello F, Carucci P, Musso A, De Paolis P, Capussotti L, Salizzoni M, Rizzetto M. Expanding the natural history of nonalcoholic steatohepatitis: from cryptogenic cirrhosis to hepatocellular carcinoma. Gastroenterology 2002;123:134-40.

8. Boudinaud C, Abergel A, Joubert-Zakeyh J, Fontarensky M, Pereira B, Chauveau B, Garcier JM, Chabrot P, Boyer L, Magnin B. Quantification of steatosis in alcoholic and nonalcoholic fatty liver disease: Evaluation of four MR techniques versus biopsy. Eur J Radiol 2019;118:169-74.

9. Luo XF, Yang Y, Yan J, Xie XQ, Zhang H, Chai WM, Wang L, Schmidt B, Yan FH. Virtual iron concentration imaging based on dual-energy CT for noninvasive quantification and grading of liver iron content: An iron overload rabbit model study. Eur Radiol 2015;25:2657-64.

10. Szymczak A, Simon K, Inglot M, Gladysz A. Safety and effectiveness of blind percutaneous liver biopsy: analysis of 1412 procedures. Hepat Mon 2012;12:32-7.

11. Weigand K, Weigand K. Percutaneous liver biopsy: retrospective study over 15 years comparing 287 inpatients with 428 outpatients. J Gastroenterol Hepatol 2009;24:792-9.

12. Henninger B, Alustiza J, Garbowski M, Gandon Y. Practical guide to quantification of hepatic iron with MRI. Eur Radiol 2020;30:383-93.

13. Hu F, Yang R, Huang Z, Wang M, Yuan F, Xia C, Wei Y, Song B. 3D Multi-Echo Dixon technique for simultaneous assessment of liver steatosis and iron overload in patients with chronic liver diseases: a feasibility study. Quant Imaging Med Surg 2019;9:1014-24.

14. Kühn JP, Hernando D, Muñoz del Rio A, Evert M, Kannengiesser S, Völzke H, Mensel B, Puls R, Hosten N, Reeder SB. Effect of multipeak spectral modeling of fat for liver iron and fat quantification: correlation of biopsy with MR imaging results. Radiology 2012;265:133-42.

15. Hyodo T, Yada N, Hori M, Maenishi O, Lamb P, Sasaki K, Onoda M, Kudo M, Mochizuki T, Murakami T. Multimaterial Decomposition Algorithm for the Quantification of Liver Fat Content by Using FastKilovolt-Peak Switching Dual-Energy CT: Clinical
Evaluation. Radiology 2017;283:108-18.

16. Schwenzer NF, Springer F, Schraml C, Stefan N, Machann J, Schick F. Non-invasive assessment and quantification of liver steatosis by ultrasound, computed tomography and magnetic resonance. J Hepatol 2009;51:433-45.

17. Pickhardt PJ, Graffy PM, Reeder SB, Hernando D, Li K. Quantification of Liver Fat Content with Unenhanced MDCT: Phantom and Clinical Correlation with MRI Proton Density Fat Fraction. AJR Am J Roentgenol 2018;211:W151-7.

18. Fischer MA, Gnannt R, Raptis D, Reiner CS, Clavien PA, Schmidt B, Leschka S, Alkadhi H, Goetti R. Quantification of liver fat in the presence of iron and iodine: an ex-vivo dual-energy CT study. Invest Radiol 2011;46:351-8.

19. Fischer MA, Reiner CS, Raptis D, Donati O, Goetti R, Clavien PA, Alkadhi H. Quantification of liver iron content with CT-added value of dual-energy. Eur Radiol 2011;21:1727-32.

20. Li C, Ye J, Peng Y, Dou W, Shang S, Wu J, Jafari R, Gillen KM, Wang Y, Prince M, Luo X. Evaluation of diffusion kurtosis imaging in stratification of nonalcoholic fatty liver disease and early diagnosis of nonalcoholic steatohepatitis in a rabbit model. Magn Reson Imaging 2019;63:267-73.

21. Patino M, Prochowski A, Agrawal MD, Simeone FJ, Gupta R, Hahn PF, Sahani DV. Material Separation Using Dual-Energy CT: Current and Emerging Applications. Radiographics 2016;36:1087-105.

22. Wu Q, Fu X, Zhuo Z, Zhao M, Ni H. The application value of ultra-short echo time MRI in the quantification of liver iron overload in a rat model. Quant Imaging Med Surg 2019;9:180-7.

23. Luo XF, Xie XQ, Cheng S, Yang Y, Yan J, Zhang H, Chai WM, Schmidt B, Yan FH. Dual-Energy CT for Patients Suspected of Having Liver Iron Overload: Can Virtual Iron Content Imaging Accurately Quantify Liver Iron Content? Radiology 2015;277:95-103.

24. Albrecht MH, De Cecco CN, Schoepf UJ, Spandorfer A, Eid M, De Santis D, Varga-Szemes A, van Assen M, von Knebel-Doeberitz PL, Tesche C, Puntmann VO, Nagel E, Vogl TJ, Nance JW. Dual-energy CT of the heart current and future status. Eur J Radiol 2018;105:110-8.

25. Li JH, Tsai CY, Huang HM. Assessment of hepatic fatty infiltration using dual-energy computed tomography: a phantom study. Physiological measurement 2014;35:597-606.

26. Ma J, Song ZQ, Yan FH. Separation of hepatic iron and fat by dual-source dual-energy computed tomography based on material decomposition: an animal study. PloS 
one 2014;9:e110964.

27. Xie T, Li Y, He G, Zhang Z, Shi Q, Cheng G. The influence of liver fat deposition on the quantification of the liver-iron fraction using fast-kilovolt-peak switching dual-energy CT imaging and material decomposition technique: an in vitro experimental study. Quant Imaging Med Surg 2019;9:654-61.

Cite this article as: Peng Y, Ye J, Liu C, Jia H, Sun J, Ling J, Prince M, Li C, Luo X. Simultaneous hepatic iron and fat quantification with dual-energy $\mathrm{CT}$ in a rabbit model of coexisting iron and fat. Quant Imaging Med Surg 2021;11(5):2001-2012. doi: 10.21037/qims-20-902 
Supplementary

Table S1 Correlation between Iron- ${ }_{\mathrm{CT}}(\mathrm{X})$ and $\mathrm{LIC}(\mathrm{Y})$ at different hepatic fat levels

\begin{tabular}{|c|c|c|c|c|c|}
\hline Fat grade & Correlation coefficient $(r)$ & $P$ value & Linear equation & $P$ value & $F$ value \\
\hline Mild steatosis $(n=12)$ & 0.92 & $<0.001$ & $Y=0.38^{\star} X-3.859$ & $<0.001$ & 58.49 \\
\hline Moderate \& severe steatosis $(n=14)$ & 0.93 & $<0.001$ & $Y=0.29^{*} X-0.1291$ & $<0.001$ & 72.92 \\
\hline
\end{tabular}

Table S2 Correlation between Fat-CT (X) and Fat-ref $(\mathrm{Y})$ at different hepatic iron levels

\begin{tabular}{|c|c|c|c|c|c|}
\hline Iron grade & Correlation coefficient(r) & $P$ value & Linear equations & $P$ value & F value \\
\hline Mild iron overload ( $\mathrm{n}=7$ ) & 0.95 & 0.001 & $Y=1.85^{\star} X+11.97$ & 0.001 & 45.78 \\
\hline Moderate iron overload $(n=8)$ & 0.89 & 0.003 & $Y=1.64^{*} X+16.28$ & 0.003 & 23.68 \\
\hline Severe iron overload $(n=9)$ & 0.89 & 0.001 & $Y=1.65^{\star} X+10.16$ & 0.001 & 27.21 \\
\hline
\end{tabular}

